\title{
The Dynamics of Vasopressin Release and Blood Volume Regulation During Fetal Hemorrhage in the Lamb Fetus
}

\author{
JEAN E. ROBILLARD, RICHARD E. WEITZMAN, DELBERT A. FISHER, AND FRED G. SMITH, JR. \\ Department of Pediatrics, University of Iowa, Iowa City, Iowa, and Departments of Medicine and Pediatrics, UCLA- \\ Harbor General Hospital, Torrance, California, USA
}

\begin{abstract}
Summary
Experiments were performed on 11 long-term fetal lamb preparations (103-138 days of gestation) to investigate the sensitivity and relative responsiveness of the fetal volume receptors in modulating fetal plasma arginine vasopressin (pAVP) secretion and plasma renin activity (PRA) secretion during fetal hypovolemia and after fetal blood volume replacement. During fetal hemorrhage there were significant decreases $(P<0.05)$ in fetal hematocrit $(34.7 \pm 2.58$ to $27.0 \pm 1.64 \%)$, plasma proteins $(3.14 \pm 0.15$ to 2.78 $\pm 0.19 \mathrm{~g} / 100 \mathrm{ml})$, mean arterial blood pressure (MABP) $(58.1 \pm$ 2.59 to $52.2 \pm 2.60 \mathrm{mmHg})$ and fetal arterial $\mathrm{pH}(7.38 \pm 0.01$ to $7.35 \pm 0.01)$. A significant increase in fetal pAVP concentration from $0.73 \pm 0.21$ to $34.9 \pm 10.04 \mu \mathrm{U} / \mathrm{ml}(P<0.01)$ and fetal PRA from $4.78 \pm 2.22$ to $40.4 \pm 18.31 \mathrm{ng} / \mathrm{ml} / \mathrm{hr}(P<0.05)$ was demonstrated at the peak of fetal hemorrhage. Two hr after correction of the fetoplacental blood volume, these values were back to base line levels. No change in either maternal pAVP or PRA was seen during fetal hemorrhage. When individual values for log PAVP and log PRA were plotted as a function of percent of fetoplacental blood volume removed the correlation coefficients were 0.82 and 0.60 , respectively. A multiple regression analysis showed a high correlation of $\log$ pAVP and $\log$ PRA with the volume of blood removed and a low partial correlation with the fetal MABP. This suggests the decrease in fetal MABP was not the primary factor explaining the increase in pAVP and PRA during fetoplacental blood volume depletion. The data indicate that the fetal volume receptors for control of arginine vasopressin secretion are fully functional in the last trimester of gestation and suggests that fetal pAVP and PRA are released as an exponential function of the percent of fetoplacental blood volume depletion. Finally, an isosmotic water shift from the fetal interstitial space to the fetal vascular space is described during fetal hemorrhage.
\end{abstract}

\section{Speculation}

It is suggested that a change in the equilibrium between the forces regulating fluid movement through the fetal capillary membranes, in accordance with Starling's principle, activates isosmotic water fluxes from the fetal interstitial space to the fetal vascular compartment counteracting the effects of fetal blood volume depletion. Therefore, the role of arginine vasopressin (AVP) release during fetal hemorrhage, if any, will be to act as a pressor substance helping to maintain fetal blood pressure. No major effect of AVP on placental membranes was demonstrated in vivo.

Available information suggests that the newborn is capable of secreting vasopressin at birth and that both the osmoreceptors and volume control systems are fully functional $(14,21,22)$.

During fetal life, the increase in concentration of circulating vasopressin has been evoked by either osmolar or volume stimuli, using shnrt-term fetal lamb preparations (exteriorized fetuses) (3,
32). However, the effects of surgical stress and anesthesia on the fetus may themselves have influenced this response $(15,17)$. Recently, using long-term fetal lamb preparations (chronically catheterized) and avoiding the effects of surgical stress on the fetus, we demonstrated that the fetal osmoreceptor system for control of AVP secretion is fully functional in the last trimester of pregnancy (38).

The present protocol was designed to study the responsiveness of the fetal hypothalamic neurohypophyseal system to a hemorrhagic stimulation under conditions that approximate the usual physiologic situation using long-term fetal lamb preparations. Using a specific and sensitive radioimmunoassay for AVP (34), we were able to assess the sensitivity and relative responsiveness of the fetal volume receptors in modulating fetal AVP secretion during fetal hypovolemia and after fetal blood volume replacement. Finally, this model permitted us to investigate the physiologic mechanisms regulating the fetal blood volume during fetal hemorrhage.

\section{METHODS}

Eleven pregnant, mixed breed Dorset-Suffolk ewes, between 103-138 days of gestation (term, 145 days) were obtained from a local source. Gestational ages were estimated according to the induced ovulation technique (23). The intrauterine fetal weight at the time of the experiment was estimated according to the equation formulated by Gresham et al. (18).

In all fetuses, the chronic indwelling catheter preparation was used as previously described (29). Briefly, under halothane anesthesia, polyethylene catheters were passed into the fetal femoral artery and vein. A catheter was also placed in a superficial tributary of a maternal femoral artery. After surgery, the ewes were kept in a restricted area and fed a standard sheep chow. The animals were usually standing and eating within $1 \mathrm{hr}$ postsurgery. Ampicillin ( $1 \mathrm{~g}$ every $8 \mathrm{hr}$ ) was given intramuscularly for the first 3 days after surgery.

\section{PHYSIOLOGIC STUDIES}

Experiments were not conducted before the 6 postoperative days. After control collection of fetal arterial blood for $\mathrm{pH}$, blood gases, plasma electrolytes $\left(\mathrm{Na}+, \mathrm{K}+, \mathrm{Cl}^{-}\right)$, plasma osmolality, total plasma protein, hematocrit, and determination of PRA and pAVP, fetal hemorrhage was performed in a steplike fashion. Fetal blood $(25 \mathrm{ml})$ was removed in heparinized syringes every 10 min up to a volume estimated between $25-30 \%$ of the total fetoplacental blood volume. In four animals, the blood removed was between $30-35 \%$ of the total volume. The total fetoplacental blood volume $(135 \mathrm{ml} / \mathrm{kg})$ was estimated from the data of Creasy et al. (9). During fetal hemorrhage, arterial fetal blood samples were collected in between every fetal blood removal period.

Thereafter, the total fetal blood removed was returned to the fetal circulation. When necessary, maternal blood was added to 
the fetal volume to compensate for the fetal blood volume used for fetal blood samples. Another fetal blood sample was taken 120 min after the fetal blood was returned. Fetal blood pressure was monitored throughout using a Statham $\mathrm{P}_{23} \mathrm{Db}$ strain gauge transducer (40), but was not corrected for intrauterinte pressures.

Maternal blood samples were also monitored for PRA and pAVP before, during, and $120 \mathrm{~min}$ after fetal hemorrhage.

\section{ANALYTIC METHODS}

All blood samples for AVP and PRA measurements were collected in chilled tubes containing potassium EDTA, kept on ice and centrifuged immediately at $4^{\circ} \mathrm{C}$. Vasopressin (34) and PRA $(19,27)$ were measured by radioimmunoassays. Sodium and potassium concentrations were measured with a flame photometer (41) and chloride concentration by potentiometric titration using a chloridometer (42). Blood osmolality was determined by freezing point depression employing an osmometer (43). Arterial fetal blood for $\mathrm{pH}, \mathrm{PCO}_{2}$, and $\mathrm{PO}_{2}$ was collected anaerobically in heparinized glass syringes and immediately determined with the appropriate $\mathrm{pH}, \mathrm{PCO}_{2}$, and $\mathrm{PO}_{2}$ electrodes (44) at $39^{\circ} \mathrm{C}$. Protein content of fetal serum was determined using a refractometer (45).

\section{DATA ANALYSES}

The data were evaluated using the $t$ test for paired data. The regression lines were determined with the least-squares formula. Analysis of variance using the $F$ distribution was applied to test the means between different groups of data. The term "significant" is used throughout the paper to describe changes with a total $P$ value of less than 0.05 in a two-sided significance limit. The results are presented as means $\pm \mathrm{SE}$.

\section{RESULTS}

Arterial blood and plasma values for all experiments are summarized in Table 1. At the peak of fetal hemorrhage, there was a decrease in fetal $\mathrm{pH}$ from $7.38 \pm 0.01$ to $7.35 \pm 0.01(P<0.05)$ and an increase in fetal $\mathrm{PO}_{2}$ from $21.1 \pm 1.34$ to $24.9 \pm 1.32$ $\mathrm{mmHg}(P<0.05)$. Fetal plasma electrolytes and plasma osmolality remained stable during fetal hemorrhage and $120 \mathrm{~min}$ after blood volume correction when compared to control values. There were significant decreases in both fetal hematocrit from $34.7 \pm 2.58$ to $27.0 \pm 1.64 \%(P<0.05)$ and fetal plasma protein from $3.14 \pm 0.15$ to $2.78 \pm 0.19 \mathrm{~g} / 100 \mathrm{ml}(P<0.05)$ during fetal hemorrhage when compared to control values. These values returned to base line

Table 1. Changes in fetal blood and hemodynamics values during fetoplacental blood removal and $120 \mathrm{~min}$ after blood volume replacement

\begin{tabular}{lcll}
\hline & Control & Hemorrhage & Posttransfusion \\
\hline $\mathrm{pH}$ & $7.38 \pm 0.01$ & $7.35 \pm 0.01^{1,2}$ & $7.86 \pm 0.01$ \\
$\mathrm{PCO}_{2}(\mathrm{mmMg})$ & $41.9 \pm 1.40$ & $44.0 \pm 1.59$ & $45.1 \pm 2.66$ \\
$\mathrm{PO}_{2}(\mathrm{mmHg})$ & $21.1 \pm 1.34$ & $24.9 \pm 1.32^{1,2}$ & $22.1 \pm 1.76$ \\
$\mathrm{Na}^{+}(\mathrm{mEq} / \mathrm{liter})$ & $144 . \pm 1.03$ & $143 . \pm 0.94$ & $144 . \pm 0.92$ \\
$\mathrm{~K}^{+}(\mathrm{mEq} / \mathrm{liter})$ & $4.57 \pm 0.17$ & $4.72 \pm 0.24$ & $4.37 \pm 0.21$ \\
$\mathrm{Cl}^{-}(\mathrm{mEq} / \mathrm{liter})$ & $104 . \pm 1.68$ & $104 . \pm 1.58$ & $103 . \pm 2.00$ \\
Osmolality & $289 . \pm 2.12$ & $292 . \pm 2.50$ & $290 . \pm 0.93$ \\
$\quad$ & & \\
$\quad(\mathrm{mOsm} / \mathrm{kg}$ & & & \\
$\quad \mathrm{H}$ & & & \\
$\mathrm{Hematocrit}(\%)$ & $34.7 \pm 2.58$ & $27.0 \pm 1.64^{1,2}$ & $34.5 \pm 2.64^{2,3}$ \\
Total protein $(\mathrm{g} /$ & $3.14 \pm 0.15$ & $2.78 \pm 0.19^{1,2}$ & $3.14 \pm 0.22^{2,3}$ \\
$\quad$ & & & \\
$\quad$ 100 ml) & & $52.2 \pm 2.60^{1,2}$ & $58.4 \pm 3.97^{2,3}$ \\
Heart rate (beats/ & $183 . \pm 9.86$ & $205 . \pm 12.48$ & $205 . \pm 11.5$ \\
$\quad$ min) & & &
\end{tabular}

' Control vs. hemorrhage values.

${ }^{2} P<0.05$.

${ }^{3}$ Hemorrhage vs. posttransfusion values.

${ }^{4}$ MABP: mean arterial blood pressure.
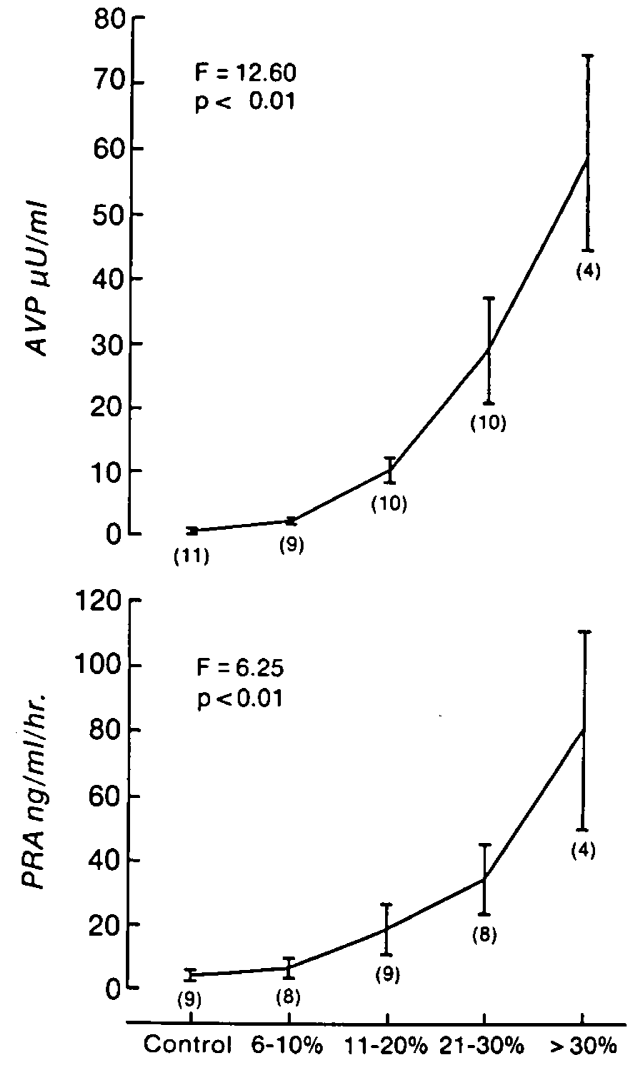

Fetoplacental Blood Volume Removed

Fig. 1. The relationship of fetal PAVP and PRA to changes in fetoplacental blood volume is shown. The figures in parentheses indicate the number of determinations for each point.

Table 2. Changes in fetal and maternal $p A V P$ and PRA during fetoplacental blood volume removal and $120 \mathrm{~min}$ after blood volume replacement

\begin{tabular}{lccc}
\hline & Control & Hemorrhage & Posttransfusion \\
\hline Fetus & & & \\
AVP $\mu \mathrm{U} / \mathrm{ml}$ & $0.73 \pm 0.21$ & $34.9 \pm 10.04^{1,2}$ & $1.77 \pm 0.67^{1,3}$ \\
PRA ng/ml/hr & $4.78 \pm 2.22$ & $40.4 \pm 18.31^{2,4}$ & $4.74 \pm 2.87^{3,4}$
\end{tabular}

Ewes

\begin{tabular}{llll} 
AVP $\mu \mathrm{U} / \mathrm{ml}$ & $1.09 \pm 0.32$ & $1.38 \pm 0.46$ & $0.58 \pm 0.12$ \\
$\mathrm{PRA} \mathrm{ng} / \mathrm{ml} / \mathrm{hr}$ & $1.45 \pm 0.34$ & $1.15 \pm 0.23$ & $1.47 \pm 0.38$ \\
\hline${ }^{1} P<0.01$. & \\
${ }^{2}$ Control versus hemorrhage values. \\
${ }^{3}$ Hemorrhage vs. posttransfusion values. \\
${ }^{4} P<0.05$.
\end{tabular}

levels 120 min after fetal blood volume correction. At the peak of fetal hemorrhage the fetal MABP was significantly lower $(P<$ 0.05 ) than control values and values found $2 \mathrm{hr}$ after fetal blood volume replacement.

The changes in the levels of PAVP and PRA after fetal hemorrhage are shown in Table 2. A significant increase in fetal pAVP from $0.73 \pm 0.21$ to $34.9 \pm 10.04 \mu \mathrm{U} / \mathrm{ml}(P<0.01)$ and fetal PRA from $4.78 \pm 2.22$ to $40.4 \pm 18.31 \mathrm{ng} / \mathrm{ml} / \mathrm{hr}(P<0.05)$ was demonstrated at the peak of fetal hemorrhage. Two hr after correction of the fetal blood volume, fetal PAVP and PRA were back to control values. No change was demonstrated during fetal hemorrhage in either maternal pAVP or PRA.

The relationships of fetal pAVP concentration and fetal PRA to isosmotic changes in fetal blood volume are shown in Figure 1. It was demonstrated that fetal pAVP and PRA rose at a significant $(P<0.01)$ increasing rate relative to the degree of hypovolemia. 

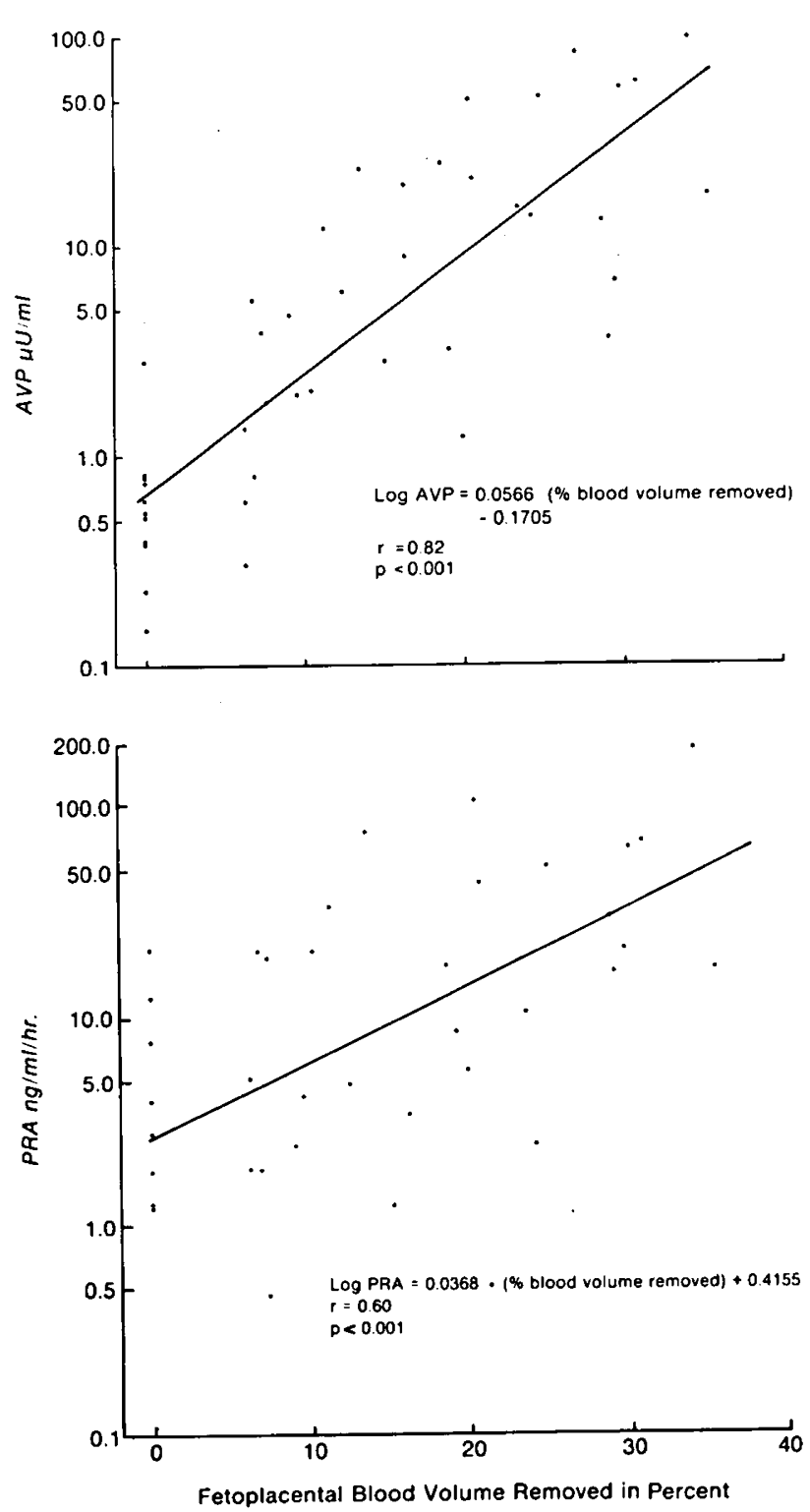

Fig. 2. Log linear relationship of fetal PAVP and PRA to the percent of fetoplacental blood volume removed is shown.

When individual values for pAVP were plotted as a function of percent of fetoplacental blood volume depletion, a linear regression of the data showed a correlation coefficient of 0.65 . However, the data were best fit by plotting the log of individual pAVP concentrations against the percent of blood volume depletion $(r$ $=0.82, P<0.001$ ) (Fig. 2). The increase in fetal PRA during blood volume depletion was also best fit by the $\log$ fit $(r=0.60$, $P<0.001)$ (Fig . 2) rather than by the linear fit $(r=0.52)$.

\section{DISCUSSION}

It has been previously demonstrated that the pituitary of mammalian fetuses contains AVP. In the human fetal pituitary, AVP has been identified as early as 11 wk of gestation $(24,33)$. In other mammalian species, including the guinea pig, rabbit, sheep, and seal, the presence of AVP has been documented in the fetal pituitary gland during the last half of gestation $(3,7,16,37)$. In addition, investigators using short-term fetal preparations in sheep and monkeys were able to measure concentrations of circulating vasopressin during the last trimester of gestation $(3,32)$. More recently, Weitzman et al. (38), using a sensitive and specific radioimmunoassay were able to measure pAVP concentrations in long-term fetal lamb preparations as early as 101 days of gestation and demonstrated that the fetal pituitary was able to release AVP in response to hypertonic saline infusion.

The response of the fetal pituitary to release AVP during fetal hemorrhage has been studied previously using short-term fetal preparations and relatively insensitive assays of hormone activity $(3,16)$. These studies demonstrated that fetal hemorrhage in such preparations increased pAVP concentrations (3); however, the effects of surgical stress and anesthesia on the fetus might have modified the normal fetal response to fetal hemorrhage $(15,17)$. Furthermore, it is well-known that reestablishment of normal fetoplacental circulation after surgery may require up to 5 postoperative days (30).

In the present study, the use of the long-term fetal preparation permits the investigators to study the relative responsiveness of the fetal volume receptors to regulate the fetal AVP secretion in well oxygenated, nonstressed fetuses. These studies confirm previous preliminary findings in the long-term fetal lamb preparation $(10,12)$ and demonstrate a significant increase in fetal plasma AVP during blood volume depletion. Moreover, it is shown that an increase in fetoplacental blood volume inhibits, as in adult animals (39), the release of vasopressin from the fetal neurohypophysis.

In the present study, the rise in PAVP appears when the fetoplacental blood loss is between $6-10 \%$, confirming previous findings in short-term fetal lamb preparations (3) and showing that the volume receptor response to hypovolemia during fetal life is similar to that in the adult animals (13). However, it remains possible that the fetus may increase pAVP in response to a smaller amount of blood volume loss, because small hemorrhages were not performed in those animals. Claybaugh and Share (8) have shown that reduction in blood volume by as little as $2.6 \%$ stimulated AVP release during continuous slow hemorrhage in anesthetized adult dogs. In the present protocol, the fetal pAVP levels were already three times higher $(2.32 \pm 0.64 \mu \mathrm{U} / \mathrm{ml})$ than the control values $(0.73 \pm 0.21 \mu \mathrm{U} / \mathrm{ml})(P<0.05)$ when the fetoplacental blood volume was reduced by 6-10\% (Fig. 1), suggesting that the threshold for vasopressin release during fetal life is probably lower than a $6 \%$ reduction in fetoplacental blood volume. In favor of such an hypothesis, an exponential relationship is described between fetal pAVP concentration and the percent change in fetoplacental blood volume such that the log of pAVP is a linear function of percent change in blood volume (Fig. 2). Finally, we found that the pAVP response to fetal blood volume depletion is not related to fetal age with similar responses being observed in fetuses from 103-138 days of gestation. We also demonstrated no correlation between fetal and maternal levels during fetal blood volume loss suggesting an absence of placental transfer of fetal pAVP to the mother and a relative placental impermeability to vasopressin. Studies by Alexander et al. $(1,2)$ and Czernickow et al. (10) also suggested that AVP does not cross the placenta.

When the fetal pAVP values obtained after fetoplacental blood volume depletion are compared to the values obtained during fetal hypertonic saline infusion (38), it is found that the levels measured during volume depletion greatly exceed the levels achieved under hyperosmotic stimulus (38). These results suggest that, in terms of plasma concentration that can be achieved, reduction of fetal blood volume is a far more potent stimulus for the release of fetal AVP than is an increase in fetal plasma osmolality. However, when compared on the basis of percent change, small changes in osmolality (38) are more efficient in stimulating vasopressin secretion than small changes in blood volumes. Thus, it suggests that in fetuses like in adults, the osmoregulatory system is more sensitive than the volume receptor system in regulating AVP release (13).

During hemorrhage, the primary stimulus for vasopressin release is probably the reduction of blood volume. However, some investigators suggested that a fall in arterial pressure is the prime stimulus for vasopressin release during blood volume depletion $(4,6)$. Similarly, recent studies using both short-term (35) and long-term fetal lamb preparations (28) indicated that fetal plasma 
renin activity increased significantly during fetal blood volume reduction. In the present study, a slight, but significant difference is found between fetal MABP before hemorrhage and at the peak of fetoplacental blood volume loss. However, no significant difference is found when the mean arterial blood pressure before fetal hemorrhage is compared to blood pressure corresponding to 6-10\% or $11-20 \%$ fetal blood volume loss. Moreover, a multiple regression analysis shows a high correlation of $\log \mathrm{pAVP}$ and $\log$ PRA with the volume of blood removed and a low partial correlation with the fetal MABP. Therefore, during fetoplacental blood volume loss, the rise in PRA and the increased release of vasopressin by the fetal neurohypophysis do not depend solely on a reduction in arterial pressure, suggesting an important role of the fetal volume receptors in the normal physiologic control of these two hormone systems.

The physiologic role of AVP in the fetal animal is still unclear. Alexander et al. (1) suggested that the release of fetal AVP in response to fetal hypoxia may have some survival values during fetal life. Daniel et al. (11) demonstrated that fetal pAVP increased after occlusion of the umbilical cord, suggesting that fetal AVP might have a role to play in the defense against metabolic derangements caused by brief periods of cord occlusion. In the present study, we have indirect evidence that there are physiologic mechanisms counteracting the effects of fetal hemorrhage. Significant decreases in fetal hematocrit and plasma proteins without any significant change in plasma osmolality and sodium concentration were found during fetal hemorrhage indicating an isosmotic water shift in the direction of the fetal vascular space. A similar fall in fetal hematocrit during fetal hemorrhage was also observed previously by Alexander et al. (3).

Various factors may explain this isosmotic water shift during fetal hemorrhage. First, the decrease in fetal MABP during fetal blood loss may increase the hydrostatic pressure gradient between maternal and fetal circulations with resultant ultrafiltration of protein-free plasma (isosmotic water) into the fetal circulation. Such a mechanism implies that the diffusion rate of water and electrolytes across the placenta are similar. However, studies in the sheep (26), monkey (5), and human placenta (31) demonstrated that the placental membranes limit transplacental diffusion of electrolytes $\left(\mathrm{Na}+, \mathrm{Cl}^{-}\right)$, but not water. Therefore, a simple disequilibrium in the hydrostatic pressure gradient between maternal and fetal circulations is unlikely to be the explanation for the present findings.

Second, AVP, which is known to increase water fluxes from the maternal to the fetal side of the placental membranes (25), may have altered placental water permeability and induced a net flow of water from mother to fetus. Such changes probably didn't occur, however, because fetal plasma osmolality and sodium concentration remained stable in the face of the dilution in fetal plasma protein and hematocrit. It remains possible that AVP shown to stimulate sodium transport in many tissues (20), may have simultaneously increased the transplacental fluxes of electrolytes and water, producing an isosmotic water shift in the direction of the fetal vascular space. Such an AVP action on the placental membranes, however, remains to be demonstrated.

The only hypothesis remaining then, is that the shift of isosmotic water in the direction of the fetal vascular space during fetal hemorrhage is secondary to the absorption of fluids from the fetal interstitial space. When the fetal MABP decreases there is a disequilibrium between the forces regulating fluid movement through the capillary membranes in favor of a net absorption of isosmotic fluid into the fetal capillary circulation in accordance with the Starling's principle (36). Therefore, the present study demonstrates that under conditions of acute fetal hemorrhage, the fetus may protect itself against hypovolemia by replacing blood volume loss at the expense of the fetal interstitial fluid volume. The inability of the present study to demonstrate a water shift from maternal to fetal circulation does not completely exclude, however, the role. of such a mechanism to protect fetal blood volume because water movement might be detectable using more precise methods.
The physiologic significance of the rise in plasma AVP and PRA, and possibly angiotensin-II, is probably that these vasoactive peptides act to maintain fetal blood pressure in the face of hypovolemia. In the present study, the fall in fetal MABP during hemorrhage is significant, but rather small $(6 \mathrm{mmHg})$ when one considers the degree to hypovolemia achieved $(25-35 \%$ of the fetoplacental blood volume). It is also possible that other vasoactive hormones are secreted during fetal hemorrhage; and, if so, their interaction with AVP and PRA will have to be investigated.

In summary, the present study indicates that in long-term fetal lamb preparations the fetal volume receptors are active and fully functional during the last trimester of gestation. It is suggested that hypovolemia rather than the fall in arterial pressure per se is the prime stimulus for AVP liberation and rise in plasma renin activity during fetal hemorrhage. Results show that during fetal life, pAVP and PRA are released as an exponential function of the percent of fetoplacental blood volume depletion. Finally, it is suggested that there are physiologic mechanisms counteracting the effect of fetal hypovolemia by increasing isosmotic water fluxes into the fetal circulation and by maintaining fetal blood pressure; one of these mechanisms being the absorption of fluids from the fetal interstitial space.

\section{REFERENCES AND NOTES}

1. Alexander, D. P., Bashore, R. A., Britton, H. G., and Forsling, M. L.: Antidiuretic hormone and oxytocin release and antidiuretic hormone turnover in the fetus, lamb, and ewe. Biol. Neonate, 30: 80 (1976).

2. Alexander, D. P., Bashore, R. A., Britton, H. G., and Forsling, M. L.: Maternal and fetal arginine vasopressin in the chronically catheterized sheep. Biol. Neonate, 25: 242 (1974).

3. Alexander, D. P., Britton, H. G., Forsling, M. L., Nixon, D. A., and Ratcliffe, J. G.: Pituitary and plasma concentrations of adrenocorticotrophin, growth hormone, vasopressin, and oxytocin in fetal and maternal sheep during the latter half of gestation and the response to hemorrhage. Biol. Neonate, 24: 206 (1974)

4. Arnauld, E., Czernichow, P., Fumoux, F., and Vincent, J. D.: The effect of hypotension and hypovolaemia on the liberation of vasopressin during haemorrhage in the unanaesthetized monkey. Pflugers Arch., 371: 193 (1977).

5. Battaglia, F. C., Behrman, F. C., Meschia, G., Seeds, A. S., and Bruns, P. D.: Clearance of insert molecules, $\mathrm{Na}$, and $\mathrm{Cl}$ ions across the primate placenta. Am. J. Obstet. Gynecol., 102: 1135 (1968).

6. Beleslin, D., Bisset, G. W., Haldar, J., and Polak, R. L.: The release of vasopressin without oxytocin in response to haemorrhage. Proc. Roy. Soc., London. Series B, 166: 443 (1967).

7. Burton, A. M., and Forsling, M. L.: Hormone content of the neurohypophysis in foetal, newborn and adult guinea pigs. J. Physiol. (London), 221: 6P (1972).

8. Claybaugh, J. R., and Share, L.: Vasopressin, renin, and cardiovascular responses to continuous slow hemorrhage. Am. J. Physiol., 224: 519 (1973).

9. Creasy, R. K., Drost, M., Green, M. V., and Morris, J. A.: Determination of fetal, placental, and neonatal blood volumes in the sheep. Circ. Res., 27: 487 (1970).

10. Czernickow, A., Basmaciogullari, A., Toubas, P., Dumez, Y., and Tchobroutsky, C.: Arginine vasopressin secretion and placental transfer in maternal and foetal sheep. [Abstr.]. Pediatr. Res., 10: 880 (1976).

11. Daniel, S. S., Husain, K. M., Stark, R. I., Milliez, J., Yeh, M. N., and James, L. S.: Renal response in the fetal lamb to complete occlusion of the umbilical cord. [Abstr.]. Pediatr. Res. 10: 438 (1976).

12. Drummond, W. H., Rudolph, A. M., Keil, L. C., and Heymann, M. A.: Arginine vasopressin in fetal lambs and response to blood loss. [Abstr.]. Pediatr. Res., 11: 405 (1977).

13. Dunn, F. L., Brennan, T. J., Nelson, A. E., and Robertson, G. L.: The role of blood osmolality and volume in regulating vasopressin secretion in the rat. J. Clin. Invest., 52: 3212 (1973).

14. Fisher, D. A., Pyle, H. R., Porter, J. C., Beard, A. G.. and Panos, T. C.: Control of water balance in the newborn. Am. J. Dis. Child., 106: 137 (1963).

15. Forsling, M. L., and Ullmann, E.: Observations on oliguria in the anesthetized dog. [Abstr.]. Kidney Int., 8: 16 (1975).

16. Froger, J. L., Aminot, A., Debray, M. F. B., and Roffi, J.: Antidiuretic activity in the fetal and newborn rabbit hypophysis. Biol. Neonate, 30: 224 (1976).

17. Ginsburg, M., and Brown, L. M.: Effect of anaesthetics and haemorrhage on the release of neurohypophysial antidiuretic hormone. Br. J. Pharmacol. Chemother., 11: 236 (1956).

18. Gresham, E. I., Rankin, J. H. G., Makowski, E. L., Meschia, G., and Battaglia, F. C.: An evaluation of fetal renal function in a chronic sheep preparation. J. Clin. Invest., 5I: 149 (1972)

19. Haber, E., Koerner, T., Page, L. B., Kliman, B., and Purnode, A.: Application of a radioimmunoassay for angiotensin $I$ to the physiologic measurements of plasma renin activity in normal human subjects. J. Clin. Endocrinol., 29: 1349
(1969).

20. Handler, J. S., and Orloff, J.: The mechanism of action of antidiuretic hormone. In: J. Orloff and R. W. Berliner: Handbook of Physiology. Sect. 8: Renal Physiology, p. 791 (American Physiological Society, Washington, D.C., 1973). 
21. Hoppenstein, J. M., Miltenberger, F. W.. and Moran, W. H., Jr.: Antidiuretic hormone blood levels in infants from birth to three months of age. Surg. Forum, 18: 292 (1967).

22. Hoppenstein. J. M., Miltenberger, F. W., and Moran, W. H., Jr.: The increase in blood levels of vasopressin in infants during birth and surgical procedures. Surg. Gynecol. Obstet., 127: 966 (1968).

23. Jennings, J. J., and Crowley, J. P.: The influence of mating management on fertility in ewes following progesterone PMS treatment. Vet. Record., 90: 495 (1972).

24. Levina, S. E.: Endocrine features in development of human hypothalamus, hypophysis, and placenta. Gen. Comp. Endocrinol.. 11: 15I (1968).

25. Manku, M. S., Mtabaji, J. P., and Horrobin, D. F.: Effect of cortisol, prolactin, and ADH on the amniotic membrane. Nature, 258: 78 (1975).

26. Meschia, G., Battaglia, F. C., and Bruns, P. D.: Theoretical and experimental study of transplacental diffusion. J. Appl. Physiol., 22: 1171 (1967).

27. Oparil, S.: Radioassay for evaluation of renin-angiotensin-aldosterone system. p. 1-10 (Professional Education Department, G. D. Searle and Co., 1975).

28. Pipkin, F. B., Lumbers, E. R., and Mott, J. C.: Factors influencing plasma renin and angiotensin II in the conscious pregnant ewe and its foetus. J. Physiol., 243: 619 (1974)

29. Robillard, J. E., Sessions, C., Kennedy, R. L., Robillard, L. H., and Smith, F. G., Jr.: Interrelationship between glomerular filtration rate and renal transport of sodium and chloride during fetal life. Am. J. Obstet. Gynecol., 128: 727 (1977).

30. Rudolph, A. M., and Heymann, M. A.: Control of the foetal circulation. In: Foetal and Neonatal Physiology: Proceedings of the Sir Joseph Barcroft Centenary Symposium, p. 89 (Cambridge University Press, London, 1973).

31. Schneider, H., Panigel, M., and Dancis. J.: Transfer across the perfused human placenta of antipyrine, sodium and leucine. Am. J. Obstet. Gynecol., 144: 822 (1972).

32. Skowsky, W. R., Bashore, R. A., Smith, F. G., and Fisher, D. A.: Vasopressin metabolism in the foetus and newborn, In: Foetal and Neonatal Physiology: Proceedings of the Sir Joseph Barcroft Centenary Symposium, p. 439 (Cambridge University Press, London, 1973).

33. Skowsky, W. R and Fisher, D. A.: Fetal neurohypophyseal arginine vasopressin and arginine vasotocin in man and sheep. Pediatr. Res., 11:627 (197i).
34. Skowsky, W. R., Rosenbloom, A., and Fisher, D. A.: Radioimmunoassay measurement of arginine vasopressin in serum: development and application. J. Clin. Endocrinol. Metabl, 38: 278 (1974).

35. Smith, F. G., Jr., Lupu, A. N., Barajas, L., Bauer, R., and Bashore, R. A.: The renin-angiotensin system in the fetal lamb. Pediatr. Res., 8: 611 (1974).

36. Starling, E. H.: On the absorption of fluids from the connective tissue spaces. J. Physiol. (London), 19: 312 (1895).

37. Vizsolyi, E., and Perks, A. M.: New neurohypophysial principle in foetal mammals. Nature, 223: 1169 (1969).

38. Weitzman, R. E., Fisher, D. E., Robillard, J. E., Erenberg, A., Kennedy, R., and Smith, F. G.. Jr.: Arginine vasopressin response to an osmotic stimulus in the fetal sheep. Pediatr. Res., 12: 35 (1978).

39. Zehr, J. E., Johnson. J. A., and Moore, W. W.: Left atrial pressure, plasma osmolality, and ADH levels in the unanesthetized ewe. Am. J. Physiol., 217: 1672 (1969).

40. Statham Medical Instruments, Inc., Puerto Rico, 00919.

41. Instrument Laboratory, Lexington, Massachusetts.

42. Radiometer CMT-10 chloride titrator, Radiometer Co., Copenhagen, Denmark.

43. Advanced Instruments. Inc., Needham Heights, Massachusetts.

44. Radiometer PHM 72 MK2 acid base analyzer, Radiometer Co., Copenhagen, Denmark.

45. National Instrument Co., Baltimore, Maryland 21215

46. The authors thank Ms. Rubye Lawrence, Ms. Che-Ching Wang, and Ms. Anita Reviczkg for excellent technical assistance for the AVP determinations. Ms. Christine Sessions and Ms. Elli Koutsopoulos provided excellent assistance during the physiologic studies. Mr. Marilyn Simpson prepared the manuscript.

47. This research was supported by research grants HD-08953, HD-11466, HD09690 from the National Institute of Child Health and Human Development, HL-14388 from National Heart, Lung, and Blood Institute and MG-2472 from the American Heart Association.

48. Requests for reprints should be addressed to: Jean E. Robillard, M.D., Department of Pediatrics. University of lowa Hospitals, lowa City, lowa 52242 (USA).

49. Received for publication February 24, 1978

50. Accepted for publication May 18, 1978. 